\title{
Fibroelastoma dorsi
}

\section{Maribella Álvarez Rodríguez, ${ }^{1}$ Tomás González Arrona, ${ }^{1}$ Jorge Mora Constantino, ${ }^{2}$ Luis Gerardo Domínguez Carrillo ${ }^{3}$}

Paciente femenino de 58 años, empleada de negocio de telas desde hace 20 años; acude por presentar abultamiento de cinco años de evolución en región escapular izquierda, que le ocasiona discreta molestia al efectuar carga de rollos de tela en su trabajo. A la exploración se nota escápula izquierda prominente, no dolorosa al movimiento, con sensación de frote a los desplazamientos escapulares, con

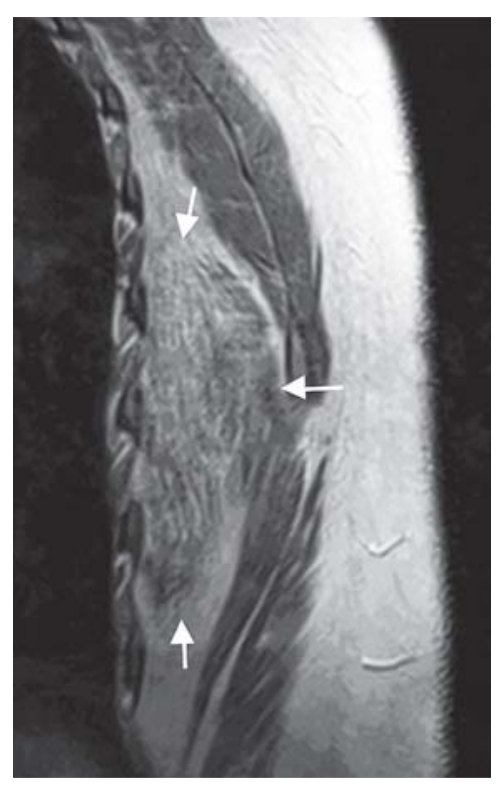

Figura 1.

Resonancia magnética en corte sagital ponderada en $\mathrm{T} 1$, que muestra masa tumoral de 9 x $3.5 \mathrm{~cm}$, hiperintensa en relación a los músculos, en contacto con los arcos costales de la superficie posterolateral del tórax, desplazando a los músculos. Corresponde clínica y radiológicamente a probable elastofibroma dorsi.

\footnotetext{
${ }^{1}$ Radiólogo. Departamento de Imagenología. Hospital Ángeles León.

2 Radiólogo. Jefe del Departamento de Imagenología. Hospital Ángeles León.

${ }^{3}$ Especialista en Medicina de Rehabilitación. Profesor de la Facultad de Medicina de León. Universidad de Guanajuato. México.
}

Correspondencia:

Dr. Luis Gerardo Domínguez Carrillo

Correo electrónico: Igdominguez@hotmail.com

Aceptado: 26-10-2016.

Este artículo puede ser consultado en versión completa en http:// www.medigraphic.com/actamedica arcos de movilidad de hombros completos y sensibilidad normal; el resto de la exploración es normal. Se solicita resonancia magnética (Figuras 1 y 2) que permite diagnóstico de probable elastofibroma dorsi (ED); se propone cirugía, la cual rechaza. El ED es un tumor infrecuente de los tejidos
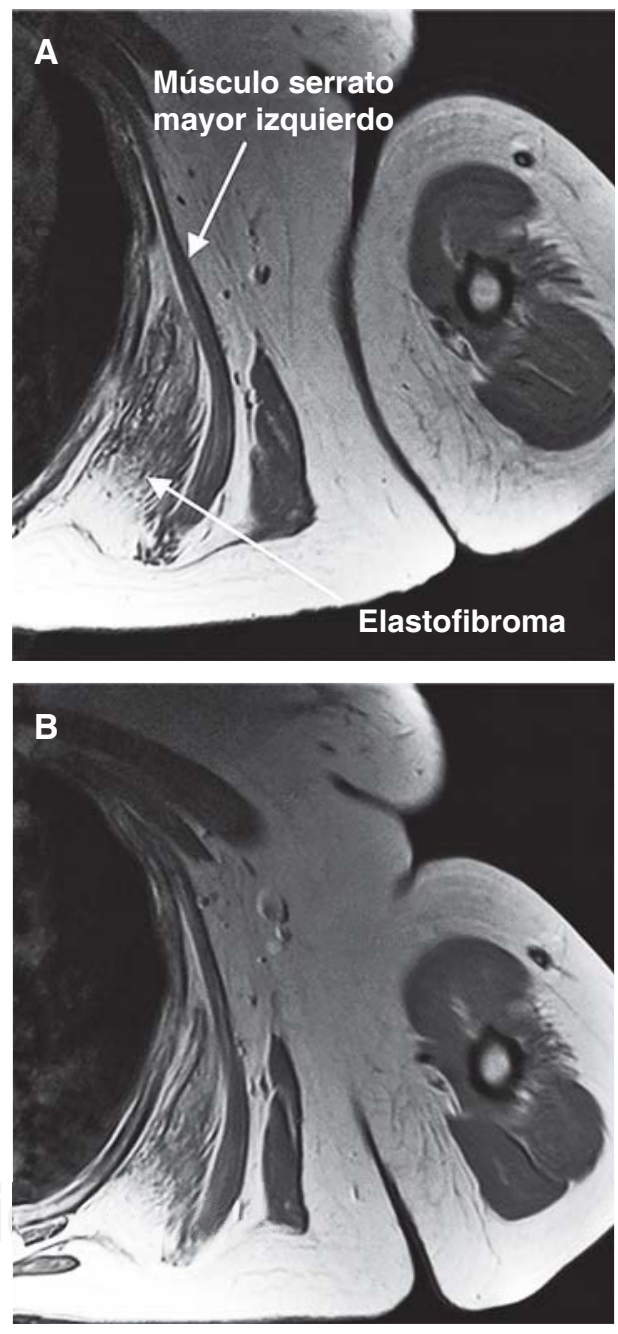

Figura 2. En A, resonancia magnética en corte axial ponderada en T1 donde se observa masa tumoral, con tejido fibroso hiperintenso, heterogéneo y con bandas de tejido adiposo interpuestas. En B, sin reforzamiento posterior a administración de gadolinio. 
blandos de la pared torácica, descrito inicialmente por Jarvi y Saxen ${ }^{1}$ en 1961; su localización más frecuente es periescapular en 99\% de los casos y anterior a la escápula sobre el plano costal, entre la sexta y la octava costilla, profundo respecto a los músculos serrato anterior, romboides y dorsal ancho. Se observa entre la cuarta y sexta décadas de la vida, con prevalencia estimada de $2 \%$, predominante en mujeres con relación $2: 1$, y predominio en hemitórax derecho; es bilateral en 10 a $60 \%$ de los casos; habitualmente asintomático; si existen síntomas se presenta dolor y frote con los movimientos escapulares. De etiopatogenia desconocida, se ha sugerido que la degeneración de las fibras de colágena es resultado de microtraumatismos repetitivos sobre la articulación escapulotorácica, induciendo proliferación excesiva de las fibras elásticas, por lo que se considera como un proceso reactivo, más que como una verdadera neoplasia. ${ }^{2}$ Histológicamente es una lesión benigna, no encapsulada, hipocelular y de contenido variable de colágeno, grasa y fibras elásticas. El diagnóstico diferencial ${ }^{3}$ debe realizarse con lesiones o tumores subcutáneos, como lipomas, fibrolipomas y neoplasias mesenquimales tipo liposarcomas, fibrosarcomas, histiocitoma fibroso, neurofibroma o metástasis. La ecografía, la tomografía computarizada y la resonancia magnética nuclear son las exploraciones complementarias más utilizadas para con- firmar el diagnóstico. En la ecografía se observa un patrón alternante, de tipo fasciculado o laminar, de líneas hipo e hiperecogénicas paralelas a la pared torácica; la señal Doppler suele ser negativa, por ausencia de vascularización. La TC muestra alternancia de tejido adiposo con densidad grasa y de tejido fibroso con densidad muscular, que no realza con medios de contraste. La $\mathrm{RM}^{4}$ es de elección para llegar al diagnóstico presentando patrón alternante de tejido adiposo y fibroso; en T1 y T2 el tejido fibroso da señales de baja intensidad similares a las del músculo. El tejido adiposo da señales de alta intensidad en T1 y señales intermedias en T2. La biopsia se reserva para los casos sospechosos que no presentan el patrón característico.

\section{REFERENCIAS}

1. Jarvi O, Saxen E. Elastofibroma dorsi. Acta Pathol Microbiol Scand Suppl. 1961; 51 (Suppl 144): 83-84.

2. Parratt MT, Donaldson JR, Flanagan AM, Saifuddin A, Pollock RC, Skinner JA et al. Elastofibroma dorsi: management, outcome and review of the literature. J Bone Joint Surg Br. 2010; 92 (2): 262-266.

3. Daigeler A, Vogt PM, Busch K, Pennekamp W, Weyhe D, Lehnhardt M et al. Elastofibroma dorsi-differential diagnosis in chest wall tumours. World J Surg Oncol. 2007; 5: 15.

4. Gao ZH, Ma L, Liu DW, Deng HF, Meng QF. Comparative study on imaging and pathological features of elastofibroma dorsi. Chin J Cancer. 2010; 29 (7): 703-708. 